\title{
An Analysis of "One Belt and One Road" under the Perspective of the Community of Common Destiny for All Mankind
}

\author{
Zhaohe Chen \\ Linyi University, Linyi, Shandong, China \\ chenzhaohe@lyu.edu.cn, fds2012@163.com
}

\begin{abstract}
Key words: the Community of Common Destiny for All Mankind; One Belt and One Road; development vision; values of the times
\end{abstract}

\begin{abstract}
From September to October 2013, President Xi Jinping proposed " One Belt and One Road " initiative and received the support and participation of more than 100 countries and international organizations. "One Belt and One Road" initiative contains China's profound historical and cultural heritage, and injects new connotations and values of the times. It has an extremely far-reaching influence and practical significance on the development of the world, countries along the line, and China. Human beings living together on the same homeland of the Earth are one community in which you have me and I have you. "One Belt and One Road" initiative is a good vision for building the Community of Common Destiny for All Mankind, a practical approach to safeguarding world peace and development, and a great cause for China's benefit to all mankind!
\end{abstract}

\section{人类命运共同体视域下的“一带一路”分析}

\author{
陈 兆 河 \\ 临沂大学, 临沂, 山东, 中国 \\ chenzhaohe@lyu.edu.cn fds2012@163.com
}

关键词: 人类命运共同体; “一带一路”; 发展愿景; 时代价值

摘要：2013年9至10月份, 习近平主席提出了“一带一路”倡议, 得到了一百多个国家和国际组 织的支持和参与。“一带一路”倡议蕴含着深厚的中国历史和文化底蕴，又注入了新的时代内 涵和时代价值，对世界、沿线国家以及中国的发展，具有极其深远的影响和现实意义。人类 共同生活在同一个地球家园，是一个你中有我、我中有你的命运共同体。“一带一路”倡议是 构建人类命运共同体的美好愿景, 是维护世界和平与发展的实践途径, 也是中国造福于全人 类的伟大事业!

\section{1. 引言}

2013年9月7日和10月3日, 国家主席习近平在出访中亚的哈萨克斯坦和东南亚的印度尼西 亚期间，先后提出了共建“丝绸之路经济带”和“21世纪海上丝绸之路”（简称“一带一路”）的 重大倡议。2015年3月28日，中国发改委、外交部和商务部联合发布了《推动共建丝绸之路经 济带和 21 世纪海上丝绸之路的愿景与行动》，强调要秉持“和平合作、开放包容、互学互鉴、 互利共赢”的丝路精神，通过深入交流和扩大合作，增进彼此之间的理解和信任，共同打造政 治互信、经济融合、文化包容的利益、命运和责任共同体，将建设目标从经济共同体扩展为 三个相互关联的共同体，形成了人类命运共同体思想，加快了推动“一带一路”建设进程。 


\section{2. “一带一路”的提出背景}

“一带一路”倡议提出以后, 迅速在全球范围内形成广泛共识, 得到了一百多个国家和国 际组织的支持和参与, 人们对古代丝绸之路的历史记忆也重新再现。“一带一路”以古代丝绸 之路为依托, 既挖掘了其深厚的历史渊源和文化底蕴, 又注入了新的时代内涵和时代价值, 重新焕发出新的生机与活力。

\section{1“一带一路”的历史渊源}

“一带一路”倡议既不是凭空产生的，也不是从零开始的，而是依托于古代丝绸之路的历 史成果, 拓展出一条能够触摸历史和祖先的民族复兴之路。从历史上看, 古代丝绸之路不仅 是当时世界上最发达的经济走廊, 更是一条连接东西方文明的桥梁和纽带。在西汉时期张骞 奉汉武帝之命出使西域, 中国人第一次认识和打通了这片广阔地域。随后一条以丝绸贸易为 主的商路, 从汉帝国都城长安出发, 途径河西走廊, 越过帕米尔高原, 走向中亚、西亚, 直 达地中海沿岸国家，把欧亚大陆的贸易通道逐渐连接起来。

中国商人频繁往返于这条商路, 不仅将丝绸、瓷器、铁器等商品输入了西方, 也将中国 的养蚕术、造纸术、印刷术、治铁术和火药等发明创造传向了西方, 向世界展示了古老的东 方智慧和中华文明。同时, 他们也为中国带来了亚麻、胡椒、香料、葡萄和石榴等新鲜物产, 还将西方的文化、思想、科技、艺术和宗教带回了中国，扩大了东西方文化的交流与合作。 1877年, 德国地理学家李希霍芬在《中国——亲身旅行和据此所作研究的成果》一书中, 将 这条连接东西方的贸易通道命名为丝绸之路。

就在陆上经济走廊被打通的同时, 海上经济通道也被逐渐开辟出来。一艘艘商船从中国 东南沿海出发, 经过马六甲海峡, 穿越印度洋进入红海, 最终抵达东非和欧洲, 海洋贸易随 之迅速发展起来。随着海洋贸易的兴起与繁荣, 广州、泉州、宁波等沿海城市, 逐步发展成 为中国重要的港口和繁荣的商埠。对这条古代中国连接东南亚、南亚、阿拉伯半岛、东非和 欧洲的海上贸易通道, 法国汉学家沙畹于1913年在《西突厥史料》一书中首次命名为海上丝 绸之路。

从陆地和海洋延伸出来的无数条贸易路线, 将不同历史时期的欧亚非国家紧密联系起来, 而这些连接世界各民族的贸易交通要道, 几乎穿越了整个旧世界版图, 被形象地称作经济全 球化的早期版本。通过这条当时世界上最长的丝绸之路, 将东西方的经济、政治和文化连接 在一起, 构筑起一张沟通东西方的复合网络, 在古代各国文明交往中发挥了巨大作用, 推动 了人类社会的发展和进步。

\section{2“一带一路”的时代要求}

当今世界正发生着深刻复杂变化, 各国相互联系、相互依存的程度日益加深, 虽然和平 与发展仍然是时代主题, 但人类面临着一系列纷繁复杂的挑战: 全球经济形势不容乐观, 各 国发展问题依然严峻, 地区热点问题此起彼伏, 恐怖主义、气候变化等非传统安全威胁持续 蔓延, 最为突出的是贫富差距进一步拉大。针对这些全球性问题, 没有哪个国家能够置之度 外、独善其身, 也没有哪个国家能够固步自封、独自应对。因此, 迫切需要探索一种新的理 念和路径来解决这些问题。

作为全球地缘政治的中心地带, 欧亚大陆更呈现出特殊的发展特征。它的一端是充满活 力的亚太经济圈, 另一端是高度发达的欧洲经济圈, 而广阔的中间腹地则是广大的发展中国 家, 不均衡发展构成了欧亚大陆区域经济格局的最显著特征。如何使发展变得更为均衡普惠, 如何使合作变得更加互利共赢, 而且能够顺利实现各国之间的发展战略对接, 成为欧亚各国 都必须认真思索和应对的首要问题。

作为连接中西方经济、政治和文化交流的主要通道, 古代丝绸之路在沉寂了数百年之久, 在经济全球化深入发展的今天，重新发挥出历史的光和热。由此“一带一路”倡议的提出和实 
施, 正是顺应了区域经济合作的时代潮流, 契合沿线国家和地区发展的迫切需要, 以一种全 新的形式把各国紧密联系起来, 齐心协力、共同携手, 推动建设开放型世界经济, 促进人类 命运共同体的构建。

\section{3.“一带一路”的发展愿景}

为了解决人类面临的共同发展困境, 不断加强国际合作力度, 探索一条惠及大多数国家 的发展道路, 自然也就成了各国共同的追求目标。中国提出了“一带一路”倡议, 旨在通过促 进共同发展和繁荣来实现合作共赢, 通过增进相互理解和信任来实现交流合作, 为推动构建 人类命运共同体提供了新的实践途径。这正是中国积极参与全球治理、共创人类美好未来的 宏伟方案。

\section{1“一带一路”的建设目标}

人类命运共同体是中国对世界前途和中国道路作出的一种战略判断和战略选择，也是中 国为人类美好未来而提出的中国智慧和中国方案。“一带一路”则是中国为构建人类命运共同 体而规划的美好愿景和建设目标, 是中国为构建人类命运共同体而进行的伟大实践和现实途 径。“一带一路”聚焦于各国人民追求和平与发展的共同梦想, 不仅将“陆”和“海”连接起来, 而且把“民”与“心”联结起来，把快速发展的中国同沿线国家的命运结合起来，搭建起一个利 益共享、责任共担、命运与共的合作平台。

从人类社会的发展全局来看, “一带一路”建设过程是欧亚非大陆经济发展的过程, 也是 东西方文明交流互鉴的过程, 更是规划人类美好未来、推动构建人类命运共同体的过程。由 于东西方文明和价值观念的冲突, 这个过程必然会产生这样或那样的问题, 中国希望世界各 国能够同舟共济、协调行动, 致力于构建一个公正合理的国际新秩序, 共同促进世界的和平 与发展。同时, 中国的现代化进程迅速加快, 在资金、技术、资源和能源等方面, 能够与沿 线国家更好地实现优势互补, 获得新的发展动力与运行载体, 从而促进各国的经济、政治和 文化的交流与合作。

\section{2“一带一路”的实践成效}

“一带一路”倡议是中国提出的第一个全球战略, 体现了中国由大国发展到强国阶段后构 建人类命运共同体的宏大胸怀。“一带一路”强调的是“共商、共建、共享”原则，旨在通过对 沿线国家实施“五通”政策, 即政策沟通、设施联通、贸易畅通、资金融通、民心相通, 实现 国家间发展战略的对接和优势互补。目前, 一大批具有影响力的标志性项目陆续启动, 包括 俄罗斯等六国提出的欧亚经济联盟、东盟提出的互联互通总体规划、中俄蒙经济走廊、中巴 经济走廊等等，对沿线国家的经济和社会发展起到了巨大的推动作用。

在推进“一带一路”的建设过程中, 中国先后签署了一大批对接合作协议和行动计划, 与 80 多个国家和国际组织签署了合作协议, 与30多个国家在机制化产能领域展开合作, 在20多 个国家设立了 70多个经贸合作区, 对外投资总额累计超过500亿美元, 并在教育、文化、卫生 和体育等领域广泛开展合作，真切地给沿线国家带来了实惠，提高了当地人民的生活水准。 2017年5月, 中国在北京成功举办了“一带一路”国际合作高峰论坛, 各国达成了二百七十多项 合作共识、重要举措及务实成果，用实际行动证明了“一带一路”在友好通商、和平发展方面 取得的巨大成就。

\section{4. “一带一路”的时代价值}

“一带一路”建设所取得的阶段性成果，证明了这不仅是一条经济合作与贸易往来之路， 也是一条思想传播和文明交流之路, 更是一条共同合作、共享成果的和平发展之路。它不仅 有利于中国自身的发展和壮大, 推动形成全面开放新格局, 而且有利于推动沿线国家的工业 
化进程，带动沿线国家的发展和繁荣，对促进世界和平与发展、推动构建人类命运共同体， 具有极其深远的影响和现实意义。

\section{1有利于推动世界经济持续稳定发展}

近年来, 经济全球化的两面性越来越明显, 为世界经济发展既带来了良好的机遇, 也带 来了严峻的挑战。发达国家掌握着现代信息技术的主动权, 主导着经济全球化的发展方向, 左右着国际经济的“游戏规则”。整个世界尤其是发展中国家，陷入了如何发展的迷茫之中， 一边是发达国家财富的不断积累, 另一边是广大发展中国家贫困的不断加剧, 不均衡发展成 为当今世界最大的难题, 经济全球化遭遇了有史以来最大的发展瓶颈。

“一带一路”倡议的提出, 恰好为世界经济的发展困局注入了新的生机和活力。作为世界 经济增长的火车头, 中国在技术、资金、产能等方面具有明显优势, 为了实现经济要素的自 由流动、资源的高效配置以及市场的深度融合, 开展范围更大、水平更高、层次更深的区域 合作，中国通过“一带一路”建设，将这些自身优势转化为市场与合作优势，将中国的经济发 展同世界经济更加紧密联系起来, 打造开放、均衡、普惠、包容的区域经济合作架构, 不断 推动世界经济的持续稳定发展。

中国是一个负责任的世界大国，在平等的文化认同框架下谈合作，致力于共同发展和共 同繁荣。而“一带一路”秉承的是“共商、共建、共享”原则, 契合国际社会的根本利益, 彰显 了人类社会的共同理想和美好追求。中国欢迎有意参与的任何国家和经济实体，共同成为“一 带一路”的支持者、建设者和受益者, 共同探讨解决全球经济低迷的“治病良方”。这不仅是中 国实现全面开放新格局的一大创举, 也是对国际交流合作和全球治理变革的积极探索, 为推 动人类文明进步做出了重大贡献。

\section{2有利于推动沿线国家工业化进程}

“一带一路”倡议是沿线国家共同的追求目标, 需要各国的广泛参与和共同努力。沿线国 家的工业化水平普遍较低, 基本上都处于中后期发展阶段, 而中国第二产业包括以钢铁、水 泥等为代表的传统重工业, 以及一些以多晶硅为代表的新兴产业等, 却面临着产能过剩的重 大问题。中国通过进一步开拓国际市场, 打造国际合作新平台, 让充分展示创造实力的优势 产业走出去, 同时把这些国家的优势资源引进来, 实现合作双方的供需互补、各尽其能的双 赢局面。

为推动形成全面开放新格局, 中国提出“一带一路”倡议, 表明一个和平崛起的工业化大 国正在产生更大的“外溢”效应。中国将与沿线国家共同携手，加快实现产能等方面的更大范 围、更深层次和更高水平的区域经济合作, 这不仅能够实现中国产业结构的优化升级, 而且 能够推动沿线国家的工业化进程, 把沿线国家带入经济发展的快车道, 并带动和促进世界其 它国家的综合发展。

“一带一路”将沿线国家政治上的互信、经济上的互补以及地缘上的优越转化为务实合作 的优势，不仅带动了沿线国家发展战略的相互对接，发掘了区域内的经济市场潜力，促进了 各方的投资和消费增长, 而且搭建了更加深入的文化沟通平台, 增进了沿线国家的人文交流 与文明互鉴, 开辟了各国人民和谐、安宁、富裕的新生活, 共同谱写“一带一路”建设的新篇 章。

\section{5.结语}

中国自古以来就被称为“衣冠上国，礼义之邦”，不管在任何时候都愿意广交朋友，发展 同世界各国的友好伙伴关系。目前, 中国同沿线国家的关系整体上处于历史最好时期, 各国 与中国加强合作的意愿普遍上升, 各国之间的相互联系更加紧密。“一带一路”倡议的成功实 施与推进, 旨在加深中国同沿线国家的相互交流与合作, 通过与沿线国家的互联互通, 实现 
开放的全方位、立体式, 有效解决中国对外开放面临的难题, 为中国形成全面开放新格局奠 定坚实的基础。

近年来, 随着综合国力的不断提升, 中国积极参与全球治理体系变革, 树立起一个负责 任的世界大国形象。中国提出构建人类命运共同体，不仅说明中国要实现古老文明大国的崛 起, 更要以负责任的态度去建构人类文明的美好未来。“一带一路”建设不仅有利于中国的全 面开放和发展需求, 而且有利于推进世界各国的相互尊重和互利合作, 推动构建人类共同命 运体和新型全球伙伴关系框架，更好地维护世界和平促进共同发展。

\section{致谢}

本文为山东省社会科学规划研究项目《习近平总书记人类命运共同体外交战略思想研究》 （项目编号：16CZLJ04）的阶段性成果之一。

\section{References}

[1] Jinping Xi, Join Hands to Advance "One Belt and One Road" Initiative ---- Speech at the Opening Ceremony of International Summit Forum of "One Belt and One Road", People's Daily, Vol. 05, 2017.

[2] Jinping Xi, Winning the Battle to Fully Build a Well-to-do Society in an All-round Way and Winning the Great Victory of Socialism with Chinese Characteristics in the New Era ---- A Report at the 19th National Congress of the Communist Party of China, People's Daily, Vol. 10, 2017.

[3] Jiechi Yang, Promoting the Construction of the Community of Common Destiny for All Mankind (Conscientiously Studying and Propagating and Implementing the Spirit of the 19th Party Congress), People's Daily, Vol. 11, 2017.

[4] Yaojun Zhang, "One Belt and One Road": An Important Practice Path of the Community of Common Destiny for All Mankind, People's Forum, Vol. 10, 2017.

[5] Zhengrong $\mathrm{Hu}, \mathrm{Co}-\mathrm{constructing}$ the Community of Common Destiny for All Mankind: A Study of China's International Relations from the Overseas Public Opinions of "One Belt and One Road”, International Communication, Vol. 02, 2017.

[6] Xianjun Zhao, "One Belt and One Road" Strategy and the Construction of the Community of Common Destiny for All Mankind, Journal of Hunan Institute of Socialism, Vol. 01, 2016.

[7] Hao Ming, "One Belt and One Road" and "the Community of Common Destiny for All Mankind”, Journal of Central University for Nationalities, Vol. 06, 2015.

[8] Zhaohe Chen. The Practical Way of the Community of Common Destiny for All Mankind ----An Analysis of "One Belt and One Road" (ISCCAC 2018) [C]. Advances in Social Science, Education and humanities Research, Vol. 142, 2018. 